\title{
REDUCTIONS IN THE MITOCHONDRIAL DNA DIVERSITY OF CORAL REEF FISH PROVIDE EVIDENCE OF POPULATION BOTTLENECKS RESULTING FROM HOLOCENE SEA-LEVEL CHANGE
}

\author{
C. Fauvelot, ${ }^{1,2,3}$ G. Bernardi, ${ }^{4}$ And S. Planes ${ }^{1,2,5}$ \\ ${ }^{1}$ Ecole Pratique des Hautes Etudes, ESA CNRS 8046, Université de Perpignan, F-66860 Perpignan Cedex, France \\ ${ }^{2}$ Centre de Recherches Insulaires et Observatoire de l'Environnement, BP 1013, Papetoai, Moorea, French Polynesia \\ ${ }^{4}$ Department of Ecology and Evolutionary Biology, University of California Santa Cruz, Santa Cruz, California 95064 \\ E-mail: bernardi@biology.ucsc.edu \\ ${ }^{5}$ E-mail: planes@univ-perp.fr
}

\begin{abstract}
This study investigated the influence of reproductive strategy (benthic or pelagic eggs) and habitat preferences (lagoon or outer slope) on both diversity and genetic differentiation using a set of populations of seven coral reef fish species over different geographic scales within French Polynesia. We hypothesized that a Holocene sea-level decrease contributed to severe reduction of population size for species inhabiting lagoons and a subsequent decrease of genetic diversity. Conversely, we proposed that species inhabiting stable environments, such as the outer slope, should demonstrate higher genetic diversity but also more structured populations because they have potentially reached a migration-genetic drift equilibrium. Sequences of the $5^{\prime}$ end of the mitochondrial DNA (mtDNA) control region were compared among populations sampled in five isolated islands within two archipelagos of French Polynesia. For all the species, no significant divergences among populations were found. Significant differences in mtDNA diversity between lagoonal and outer-slope species were demonstrated both for haplotype diversity and sequence divergence but none were found between species with different egg types. Pairwise mismatch distributions suggested rapid population growth for all the seven species involved in this study, but they revealed different distributions, depending on the habitat preference of the species. Although several scenarios can explain the observed patterns, the hypothesis of population size reduction events relative to Holocene sea-level regression and its consequence on French Polynesia coral reefs is the most parsimonious. Outer-slope species have undergone a probable weak and/or old bottleneck (outer reefs persisted during low sea level, leading to reef area reductions), whereas lagoonal species suffered a strong and/ or recent bottleneck since Holocene sea-level regression resulted in the drying out of all the atolls that are maximum 70 meters deep. Since present sea level was reached between 5000 and 6000 years ago, different demographic events (bottlenecks or founder events) have lead to the actual populations of lagoons in French Polynesia.
\end{abstract}

Key words.-Coral reef fishes, demographic history, genetic diversity, Holocene sea-level changes, life-history trait, mitochondrial DNA.

Received March 20, 2002. Accepted February 26, 2003.

A central goal of population genetics is to understand the processes that influence the interconnectivity among populations of a species because local adaptation and eventually speciation depend on the resulting genetic structure. The main difficulty in understanding these processes is that the levels of polymorphisms and their spatial distribution observed at a given time can bear the footprints of past demographic events (still visible as long as equilibrium conditions are not reached) as well as more recent evolution such as the present levels of gene flow (Avise 1998). The full interpretation of present genetic structure needs to consider the complex interactions of biology, geography, and climatic shifts (Hewitt 2000).

Determining the processes influencing genetic divergence of populations is a problem when studying many marine species, in such a fluid system that tends to homogenize populations (Palumbi 1994). This is particularly relevant for benthic and demersal coral reef species where populations are geographically isolated because of habitat fragmentation, restricting connection through adult migration. Previous studies have examined the population genetic structure of coral reef species, as a result of larval dispersion in relation to oceanic

\footnotetext{
${ }^{3}$ Present address: Institute for Biodiversity and Ecosystem Dynamics, Universiteit van Amsterdam, Kruislaan 320, 1098 SM Amsterdam, The Netherlands; E-mail: fauvelot@science.uva.nl.
}

currents (strength and direction) and geomorphology of the reef-system (Winans 1980; Bell et al. 1982; Lacson et al. 1989; Planes 1993; Planes et al. 1993, 1996; Shulman and Bermingham 1995; Lavery et al. 1996; Benzie and Williams 1997; Palumbi et al. 1997). The potential impact of biological features was also assessed by multispecies analyses aimed at testing the influence of the duration of the pelagic larval stage (Waples 1987; Lacson 1992; Doherty et al. 1995), the reproductive strategy (Shulman and Bermingham 1995; Planes et al. 1997; Gold and Richardson 1998), and the behavior and swimming abilities of larvae (Waples 1987; Riginos and Victor 2001).

More recently, studies have demonstrated that genetic patterning of species, in nonequilibrium populations, also partially results from historic patterns such as reduction or disappearance of a suitable habitat, leading to extinction and habitat recolonizations since the last glaciations (Shulman and Bermingham 1995; Bucklin and Wiebe 1998; Nelson et al. 2000; Hickerson and Ross 2001; McGlashan and Hughes 2001). Variation in effective population size relative to sealevel changes can be strong enough to be a confounding factor for the interpretation of present genetic structure. For instance, sea-level changes can affect various coral reef types in different ways. Low sea level affects reef continuums by reducing reef areas (such as in the Caribbean; Shulman and Bermingham 1995), and it can also lead to the disappearance 
of enclosed lagoons of volcanic islands (e.g. volcanic islands in French Polynesia; Bard et al. 1996). Therefore, coral reef species exclusively inhabiting lagoons of isolated atolls and volcanic islands may have undergone a serious reduction of population size, relatively to their habitat stability during Pleistocene sea-level variations. These potential recent demographic events for lagoonal populations of coral reef species (population size reduction/extension) would create spatial homogeneity of genetic variation, which could lead to a misinterpretation of present genetic patterning (Planes et al. 1993).

The present study follows a previous study by Fauvelot and Planes (2002) that investigated, using a multispecies analysis, the factors influencing the genetic structure of coral reef fish populations in French Polynesia. The potential influence of the larval phase duration on dispersal was assessed by testing for an eventual correlation between the reproductive strategy (as schematized by the existence of pelagic or benthic eggs) and observed levels of gene flow. The potential influence of the habitat preference (lagoon or outer reef) was assessed by testing the impact of the demographic history (i.e., variation of population size in areas affected by sealevel changes during the last glaciations events) on genetic diversity and divergence. Eight species were selected from two different families according different reproductive strategies, based on egg type (Thresher 1991) and different habitat preferences (species that are mostly found in lagoons vs. species typically inhabiting the outer slope of the reef). Although comparisons of allelic frequencies among enzymatic loci revealed significant divergences over all the five sampled islands for seven of the eight species, none of the species showed a significant correlation between genetic divergences and geographical distances between sampled populations. Moreover, the levels of the present gene flow in the eight species did not appear significantly related to either reproductive strategies or habitat preferences. Several hypotheses were proposed to explain these results, such as recent differentiations occurring between populations, island model organization of the sampled populations (which would explain chaotic genetic structure), or nonequilibrium populations throughout French Polynesia. However, Fauvelot and Planes (2002) could not give a conclusive explanation of the observed present genetic structure of these eight coral reef species in French Polynesia because they lacked a temporal framework in which to interpret their results. Actually, the low rate of detectable mutations in allozymes did not allow for an estimation of a molecular clock and selection had been reported to maintain enzymatic polymorphisms in diverse marine species (Koehn et al. 1980; Pogson et al. 1995; Powers and Schulte 1998; Lemaire et al. 2000). We reanalyzed the populations of seven of the eight species from the previous study using a molecular tool considered neutral that allows access to allele coalescence and then histories of populations or species (Avise 2000). We chose the $5^{\prime}$ end of the mitochondrial DNA control region (mtCR, also called D-loop) since the generally elevated rate of base substitution makes the D-loop a marker of choice for addressing intraspecific phylogenetic questions (Meyer 1994). Furthermore, the mtDNA gives a good record of population size variations because of its smaller effective population size (a quarter of the nuclear one in gonochoric species with unbiased sex ratio; Avise 1994). We specifically focused our study on the following questions. Is there evidence that Holocene sea-level regression led to bottlenecks in lagoonal populations? If so, can we see the influence of contemporary events such as gene flow? We expect that (1) lagoonal species show reduced genetic variability among islands compared to outer-slope species because lagoons dried out during Holocene sea-level regression, leading to lagoon population size reductions; and (2) species laying benthic eggs should exhibit higher levels of population structure than do species laying pelagic eggs because of their different larval dispersion potential, when comparing species that experienced similar historical constraints.

\section{Materials And Methods \\ Samples and DNA Extraction}

The sampling scheme is the same as in Fauvelot and Planes (2002). The geomorphology of the Polynesian islands is ideal to study the impact of fragmentation on genetic divergence. Adult migration is prevented because islands are separated by deep waters, restricting migration (gene flow) to the larval stage. Five islands were sampled within French Polynesia (Fig. 1): one high volcanic island (Moorea) and one atoll (Tetiaroa) from the Society Archipelago, and three atolls from the Tuamotu Archipelago (Rangiroa, Takapoto, and Marutea). Sites were selected according to access and geographic distances between islands, to have a range of small (such as $60 \mathrm{~km}$ between Moorea and Tetiaroa), medium (about 250 $\mathrm{km}$ between Moorea and Takapoto), and large spatial scales (up to $1550 \mathrm{~km}$ between Moorea and Marutea). Such a range of geographic distances was selected to provide a potential range of genetic differentiation.

The butterflyfish (family Chaetodontidae) represented species spawning pelagic eggs. Spawning in butterflyfishes involves large groups with unbiased sex ratio (Allen et al. 1998). Eggs hatch in the open sea approximately 24 hours after their release and larvae spend on average 45 days in the pelagic environment before returning to the reefs (Hourigan and Reese 1987). The damselfish species (family Pomacentridae) produce benthic eggs. Most damselfish species are highly territorial and several days prior to spawning, the male (or in some cases both partners) selects the nesting site. Eggs are under care in the nest for a period ranging from two to seven days until hatching (Allen 1991). Larvae are pelagic and remain in the pelagic environment for an average of 25 days (Wellington and Victor 1989). Selection of species according to their habitat was based on a previous study of fish communities in French Polynesia (Galzin 1987; recent monitoring data, R. Galzin, pers. comm.). Such a protocol provided a set of eight species: Chaetodon citrinellus as the butterflyfish inhabiting lagoons; Chaetodon quadrimaculatus and Forcipiger flavissimus as butterflyfishes living on the outer slope; Pomacentrus pavo, Chrysiptera glauca, and Dascyllus aruanus as damselfishes inhabiting lagoons; and Chromis xanthura as the damselfish living on the outer slope. The standard sampling effort was 10 fishes per species, per site, but some of the species could not be found or were rare in certain localities (Table 1): Chaetodon citrinellus was not 




FIG. 1. Sampled sites in French Polynesia. Moorea is a volcanic island and Tetiaroa, Rangiroa, Takapoto, and Marutea are atolls. Tetiaroa and Moorea belong to the Society Archipelago, and Rangiroa, Takapoto, and Marutea belong to the Tuamotu Archipelago. The Society and Tuamotu Archipelagos are separated by depths up to $4000 \mathrm{~m}$ and different currents exist within these two archipelagos.

found in Marutea; Chrysiptera glauca was rare and difficult to collect at Moorea and Tetiaroa. Finally, a total of 292 individuals were collected by spearing or using an anesthetic solution for smaller fishes between March 1998 and December 2000 for DNA analysis.

Fins of each individual were fixed directly in $90 \%$ ethanol. Tissues were digested overnight at $55^{\circ} \mathrm{C}$ with $10 \mathrm{U}$ of proteinase $\mathrm{K}$ in $500 \mu \mathrm{l}$ of extraction buffer $(400 \mathrm{mM} \mathrm{NaCl}, 10$ $\mathrm{mM}$ Tris, $2 \mathrm{mM}$ EDTA, $1 \%$ SDS). DNA was purified by standard chloroform extraction and isopropanol precipitation (Sambrook et al. 1989).

\section{PCR and Sequence Analysis}

Amplification of the highly variable $5^{\prime}$ end of the mitochondrial control region (between 266 and 397 pb depending on the species) was accomplished with the universal CR-A
(TTC CAC CTC TAA CTC CCA AAG CTA G) and CR-E (CCT GAA GTA GGA ACC AGA TG) primers (Lee et al. 1995), except for Chromis xanthura, for which a specific internal primer, XAN-DL-R (AGA TGC CAG GAA TAR TTC ACC), was designed for this study to replace CR-E. Each 100- $\mu$ l PCR reaction contained 10-100 ng of DNA, 10 $\mathrm{mM}$ Tris $\mathrm{HCl}$ (pH 8.3), $50 \mathrm{mM} \mathrm{KCl}, 1.5 \mathrm{mM} \mathrm{MgCl}_{2}, 150$ $\mathrm{mM}$ of each dNTP, 2.5 units of Taq DNA polymerase (PerkinElmer, Norwalk, CT) and $0.3 \mathrm{mM}$ of each primer. Polymerase chain reaction amplification was conducted using a profile of $45 \mathrm{sec}$ at $94^{\circ} \mathrm{C}$ for the denaturation step, an annealing step of $45 \mathrm{sec}$ at temperatures ranging between 46 to $54^{\circ} \mathrm{C}$ depending on the species, and an extension step of $1 \mathrm{~min}$ at $72^{\circ} \mathrm{C}$, for 35 cycles. Reactions without genomic DNA were included in every amplification series to screen for possible foreign DNA contamination. After purification following the

TABLE 1. Number of sequenced individuals of each species within each site. $N$, total number of individuals sequenced per species. Dash indicates no available sequences. The egg type (P, pelagic eggs; B, benthic eggs) and the habitat of the adult stage (L, lagoon; OS, outer slope) are specified for each species.

\begin{tabular}{|c|c|c|c|c|c|c|c|c|}
\hline & \multirow[b]{2}{*}{ Eggs } & \multirow[b]{2}{*}{ Habitat } & \multicolumn{3}{|c|}{ Tuamotu Archipelago } & \multicolumn{2}{|c|}{ Society Archipelago } & \multirow[b]{2}{*}{$N$} \\
\hline & & & Marutea & Rangiroa & Takapoto & Tetiaroa & Moorea & \\
\hline Chaetodon quadrimaculatus & $\mathrm{P}$ & OS & 10 & 7 & 9 & 10 & 10 & 46 \\
\hline Forcipiger flavissimus & $\mathrm{P}$ & $\mathrm{OS}$ & 7 & 7 & 7 & 7 & 6 & 34 \\
\hline Chromis xanthura & $\mathrm{B}$ & $\mathrm{OS}$ & 10 & 10 & 10 & 9 & 10 & 49 \\
\hline Chaetodon citrinellus & $\mathrm{P}$ & $\mathrm{L}$ & - & 9 & 10 & 10 & 10 & 39 \\
\hline Chrysiptera glauca & $\mathrm{B}$ & $\mathrm{L}$ & 10 & 10 & 10 & - & - & 30 \\
\hline Dascyllus aruanus & $\mathrm{B}$ & $\mathrm{L}$ & 10 & 10 & 7 & 8 & 10 & 45 \\
\hline Pomacentrus pavo & $\mathrm{B}$ & $\mathrm{L}$ & 10 & 10 & 10 & 10 & 9 & 49 \\
\hline
\end{tabular}


manufacturer's protocol (Applied Biosystems, Foster City, CA), sequencing was performed using the CR-A primer after having checked that sequences obtained by sequencing in the both directions were complimentary. Sequencing was accomplished on an ABI 373 automated sequencer (Applied Biosystems).

\section{Data Analysis}

\section{Sequence diversity and variability}

Individual sequences were aligned manually. Mitochondrial DNA variability was estimated by computing haplotype and nucleotide diversities ( $H$ and $\pi$; Nei 1987) using Arlequin version 2.000 (Schneider et al. 2000). Wilcoxon-Mann-Whitney tests (WMW test) were used for significant differences in genetic diversity among species reflecting different habitat preferences or reproductive strategy. Relationships between intraspecific haplotypes within each species were assessed using the molecular-variance parsimony technique, also called minimum spanning networks (MSN; Excoffier and Smouse 1994) implemented in Arlequin (Schneider et al. 2000). Minimum spanning networks of haplotypes were computed under haplotype pairwise differences, showing the number of mutation steps between haplotypes. Obtained networks were then drawn by hand.

The vertebrate control region of mtDNA is known to have a heterogeneous rate of nucleotide substitution among sites that can be modeled by a gamma distribution specified by the parameter alpha $(\alpha)$, also called the shape parameter (Tamura and Nei 1993; Yang 1996). Moreover, nucleotide frequencies in this part of the genome are usually heterogeneous as well as transition/transversion ratios. To assess rates of sequence divergence by employing the nucleotide substitution model that fits our data best, we tested the goodness of fit of several models using Modeltest 3.06 (Posada and Crandall 1998). This test was used to avoid inconsistencies and to facilitate interspecific comparisons (Posada and Crandall $2001)$. The parameters of each model ( $\alpha$, the shape parameter of the gamma distribution and $I$, the proportion of invariable sites) were estimated from the dataset.

\section{Population subdivision}

Distances between individuals were calculated with the appropriate model for each species using PAUP 4.0 (Swofford 1998). Differences in sequence divergence levels were tested using a $t$-test to reveal the impact of habitat preferences or biological traits on divergences within species. Population subdivisions were tested using an AMOVA (Excoffier et al. 1992) implemented in Arlequin version 2.000 (Schneider et al. 2000). Genetic distances were corrected for multiple hits by the method of Kimura (1980) assuming a gamma shape parameter equal to the ones given by Modeltest 3.06 (alternative models such as HKY85 are not available in Arlequin version 2.000; see Results). For each species, we estimated the level of genetic structuring (1) within populations, (2) between populations within a region and (3) between regions. We defined regions as populations belonging to a particular archipelago since different currents exist in these regions: Marutea, Rangiroa, and Takapoto were part of the first region of the Tuamotu Archipelago, and Moorea and Tetiaroa were part of the Society Archipelago region. For Chrysiptera glau$c a$, since populations were only sampled from the Tuamotu Archipelago, the large-scale genetic structure was tested between the West Tuamotu islands (Rangiroa and Takapoto) and Marutea to test for evidence of large-scale differentiation. In addition, population divergence was estimated by computing fixation indices identical to the weighted average $F$ statistic over loci (Weir and Cockerham 1984) for both population pairs and for all populations. The significance of the fixation index deviations from values expected under the null hypothesis of genetic homogeneity was tested using a nonparametric permutation approach described in Excoffier et al. (1992).

\section{Neutrality and demographic history}

Mitochondrial DNA sequences were analyzed to test for departures from mutation-drift equilibrium with Tajima's $D$ test (Tajima 1989) using Arlequin version 2.000 (Schneider et al. 2000). Statistical significance of this neutrality test was obtained by generating samples under the hypothesis of selective neutrality and population equilibrium, using a coalescent simulation algorithm adapted from Hudson (1990). In addition, pairwise mismatch distributions (Rogers and Harpending 1992), comprised of the pairwise differences (number of site changes) between all individuals of each species, and Rogers' (1995) model of sudden population expansion were computed using Arlequin version 2.000 (Schneider et al. 2000). Corrections for multiple hits were not included in pairwise mismatch calculations and sudden expansion models. In addition, when possible, we performed the Galtier et al. (2000) test to detect diversity-reducing events in the recent history of species and distinguish between demographic (bottlenecks) and selective causes (selective sweeps) of a recent reduction of genetic variability. Such a test requires that only one mutation occur within each site, so that (1) no more than two distinct states should be observed at any site and (2) both sequence and nucleotide sites give similar phylogenetic information (Galtier et al. 2000). These restrictions limited the computation to Pomacentrus pavo and Chrysiptera glauca since the sequences of the five other species showed homoplasious sites.

\section{RESULTS}

\section{Mitochondrial DNA Sequence Variability and Allele Phylogeny}

A summary of mtDNA variation for each species and within each geographical location is given in Table 2. The total of mtCR-sequenced bases ranged from 266 bp for Forcipiger flavissimus to $397 \mathrm{bp}$ for Chaetodon citrinellus. On average, species living on the outer slope were the most variable in terms of haplotype diversity (more than 99\%) compared to lagoonal species for which it ranged from $57.2 \%$ for $\mathrm{Po}$ macentrus pavo to $98.6 \%$ for Dascyllus aruanus. These higher values of haplotype diversity in species inhabiting the outerslope compared to lagoonal species were significant (WMW test, $P=0.034$ ). On average, individual haplotypes of species inhabiting the outer slope also appeared to be more divergent 
TABLE 2. Diversity indices from sequences of mtDNA partial control region. Number of haplotypes $(k)$ was determined from alignments of sequences of length (L) from the individuals assayed $(N)$. Number of polymorphic sites (PS) is given for each species. Haplotype diversity $(H)$, nucleotide diversity $(\pi)$, and their standard deviations were calculated according to Nei (1987).

\begin{tabular}{|c|c|c|c|c|c|c|}
\hline & $N$ & $\mathrm{~L}$ & $k$ & PS & $H(\mathrm{SD})$ & $\pi(\mathrm{SD})$ \\
\hline \multicolumn{7}{|l|}{ Outer-slope species } \\
\hline Chaetodon quadrimaculatus & 46 & 395 & 42 & 83 & $0.9961(0.0055)$ & $0.0217(0.0113)$ \\
\hline Chromis xanthura & 49 & 303 & 47 & 77 & $0.9983(0.0046)$ & $0.0347(0.0178)$ \\
\hline \multicolumn{7}{|l|}{ Lagoon species } \\
\hline Chaetodon citrinellus & 39 & 397 & 25 & 36 & $0.9487(0.0241)$ & $0.0139(0.0075)$ \\
\hline Chrysiptera glauca & 30 & 396 & 14 & 15 & $0.7540(0.0849)$ & $0.0039(0.0027)$ \\
\hline
\end{tabular}

from one another in nucleotide sequences (average nucleotide diversity for the three species of $2.52 \%$ ) than individual haplotypes of lagoonal species (average nucleotide diversity for the four species of $1.02 \%$ ). However, nucleotide diversity for outer-slope species was not significantly higher than lagoonal species (WMW test, $P=0.077$ ), probably due to low effectives and the use of a nonparametric test, less powerful than a parametric one. Similar tests compared these indices relative to the reproductive strategy and were not significant.

As expected from mtDNA sequence variability, minimum spanning networks appeared more complex in species inhabiting the outer slope than in lagoonal species (Fig. 2). For outer-slope species, common haplotypes between individuals were rare and when they did exist, only two individuals shared it. For example, for Forcipiger flavissimus, one individual from Marutea and one from Moorea shared the only common haplotype found for this species, haplotype 1, whereas 32 of the 49 sequenced individuals shared the haplotype 1 in Pomacentrus pavo. The mean number of substitutions per connection between closest haplotypes was significantly higher for outer-slope species than for lagoonal species (WMW test, $P=0.0339$ ): for example, 4.26 for Chromis xanthura but only 2.125 for Chaetodon citrinellus (see Fig. 2). Overall, haplotypes from lagoonal species only differed from each other by a few nucleotides (between one and three substitutions for Pomacentrus pavo and Chrysiptera glauca, and one and six for Dascyllus aruanus and Chaetodon citrinellus if we exclude the 11 base substitutions between haplotypes 8 and 15 for Chaetodon citrinellus). The maximum numbers of nucleotide substitutions between two haplotypes were found in outer-slope species, with Chaetodon quadrimaculatus and Chromis xanthura having 26 and 24 nucleotide substitutions respectively between the most divergent haplotypes (which gives divergence percentages of 6.58 and $7.92 \%$, respectively), whereas there were only six and eight substitutions in Pomacentrus pavo and Chrysiptera glauca (divergence percentages of 1.65 and $2.02 \%$, respectively).

Evolutionary models of nucleotide substitution were similar among species. Except for Pomacentrus pavo and Chrysiptera glauca, the tests revealed that the model that best fit the data was HKY85 (Hasegawa et al. 1985) with gamma correction (Table 3). For Pomacentrus pavo and Chrysiptera glauca, the best model found was the same (HKY85) with no gamma correction, probably due to the low number of polymorphic sites in the mtDNA control region sequences for these two species. Even though the use of a common substitution model for the comparison of conspecific haplotype networks among independent species would be the conceptually correct way to analyze the data, we kept variable $\alpha$ values of the gamma correction among species since it was difficult to select a common value for all the seven species (see Table 3). When appropriate models of nucleotide substitution were applied to each species, the mean divergence between sequences ranged from $0.26 \pm 0.30 \%$ for Pomacentrus pavo (max. divergence $=1.66 \%$ ) to $4.57 \pm 2.38 \%$ for Chromis xanthura ( $\max$. divergence $=12.58 \%$ ). The divergence between individuals of outer-slope species appeared significantly higher than those of lagoon species $(t$-test, $\mathrm{t}=$ -50.090 , df $=6112, P<0.0000)$. These differences in divergence levels remained significant when using HKY 85 with no gamma correction for all the species. However, no significant difference was revealed when comparing species laying benthic eggs versus those laying pelagic eggs $(P=0.690)$.

\section{Population Subdivision}

AMOVA analysis on each species showed that 96.4-100\% of the total molecular variance was caused by the variance within populations (Table 4). Fixation indices over all populations $\left(\Phi_{\mathrm{ST}}\right)$ ranged from -0.0092 for Pomacentrus pavo to $0.0364(P=0.076)$ for Forcipiger flavissimus, but none of the species showed significant values $(P>0.05)$. This absence of differentiation was confirmed by the absence of significant values of pairwise population $F_{\mathrm{ST}}$ (data not shown). Forcipiger flavissimus was the only species that showed a significant pairwise $F_{\mathrm{ST}}$ between Marutea and Tetiaroa, the populations furthest apart $\left(F_{\mathrm{ST}}=0.17876, P=\right.$ 0.0048). All other species did not show significant pairwise $F_{\text {ST }}$ values. In keeping with the previously obtained allozymic results, there was no more geographical structure in lagoonal than in outer-slope species and no more geographical structure in benthic than in pelagic eggs species.

\section{Inference of Population History}

Since no evidence of genetic differentiation was observed for any species, all populations within each species could be grouped as a single one to conduct tests of selective neutrality and demographic history. Pairwise mismatch distributions and results of Tajima's $D$-test performed on each species are given in Figure 3. All $D$-values obtained from 

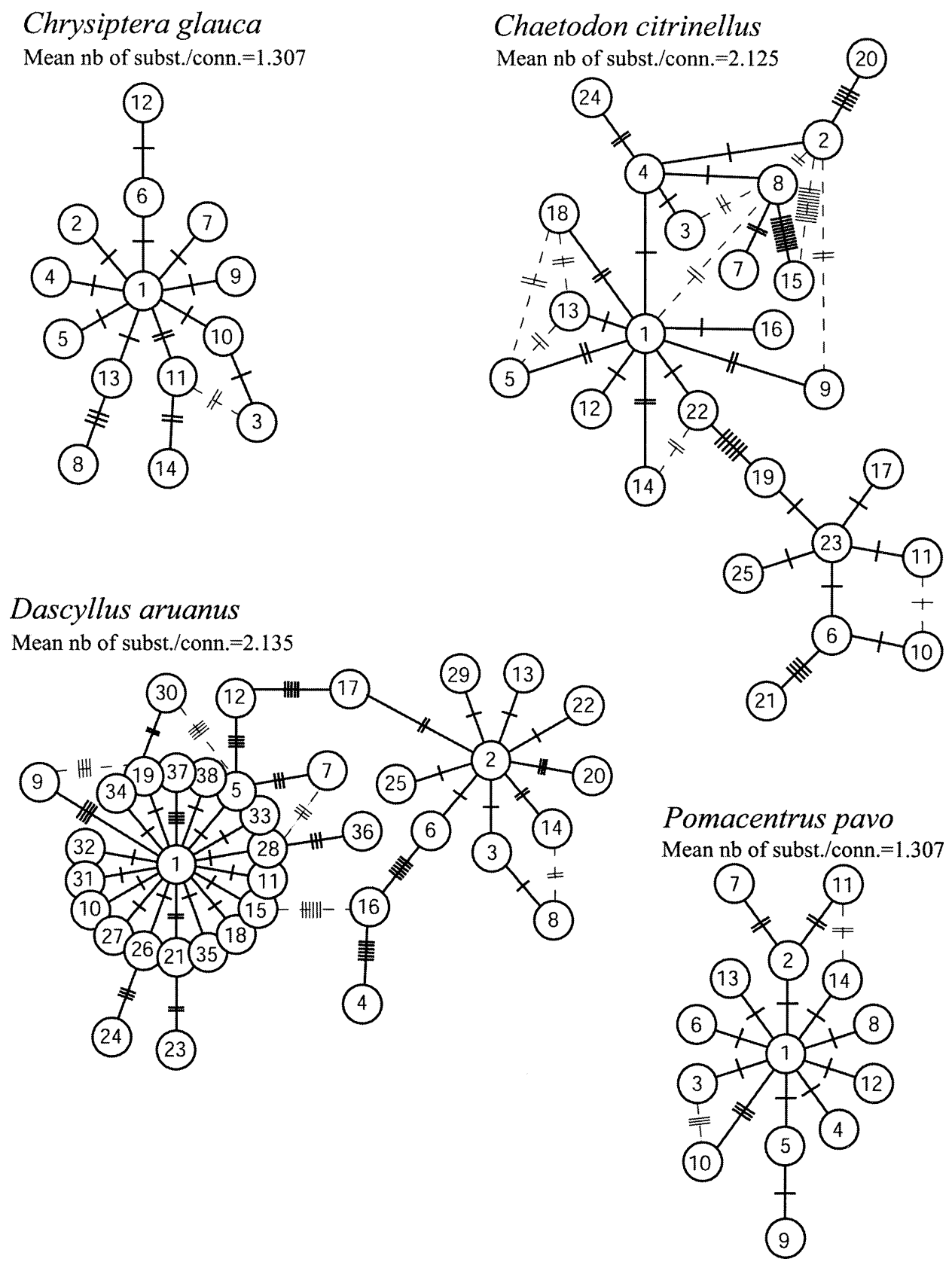

FIG. 2. Minimum spanning network of haplotypes for each species. Each number corresponds to one haplotype. Perpendicular tick marks on the lines joining haplotypes represent the number of nucleotide substitutions. After species name is the mean number of nucleotide substitutions per haplotype connection.

Tajima's $D$-tests were negative and ranged from -1.2360 $(P=0.096)$ for Chaetodon citrinellus to $-2.1303(P=$ 0.005 ) for Pomacentrus pavo. These significant negative values (indicating more rare nucleotide site variants than would be expected under a neutral model of evolution) can be the result of both selection and population expansion. Except for Chaetodon citrinellus and Chromis xanthura, the hypothesis of neutral evolution was rejected with Tajima's $D$ test. Allele phylogenies of Chaetodon citrinellus displayed using MSN revealed two different clades: the first containing haplotype 1 and the second haplotype 23 (see Fig. 2). If we applied Tajima's $D$-test to both of these clades, $D$ - values then appeared significant for the first clade $(D=$ $-1.7104, P=0.027)$, and nonsignificant for the second one $(D=-1.1278, P=0.145)$. We proceeded in the same way for Dascyllus aruanus since MSN also revealed 2 clades, one with haplotype 1 and the second with haplotype 2 . Tajima's $D$-tests on both clades revealed significant $D$-values $(D=-2.3784, P=0.001$ for the first clade and $D=$ $-1.8165, P=0.021$ for the second clade).

Distributions of pairwise differences between alleles of each species have been compared to the pairwise mismatch distribution obtained under the sudden population expansion model (Roger 1995; Fig. 3). Pairwise mismatch distributions 

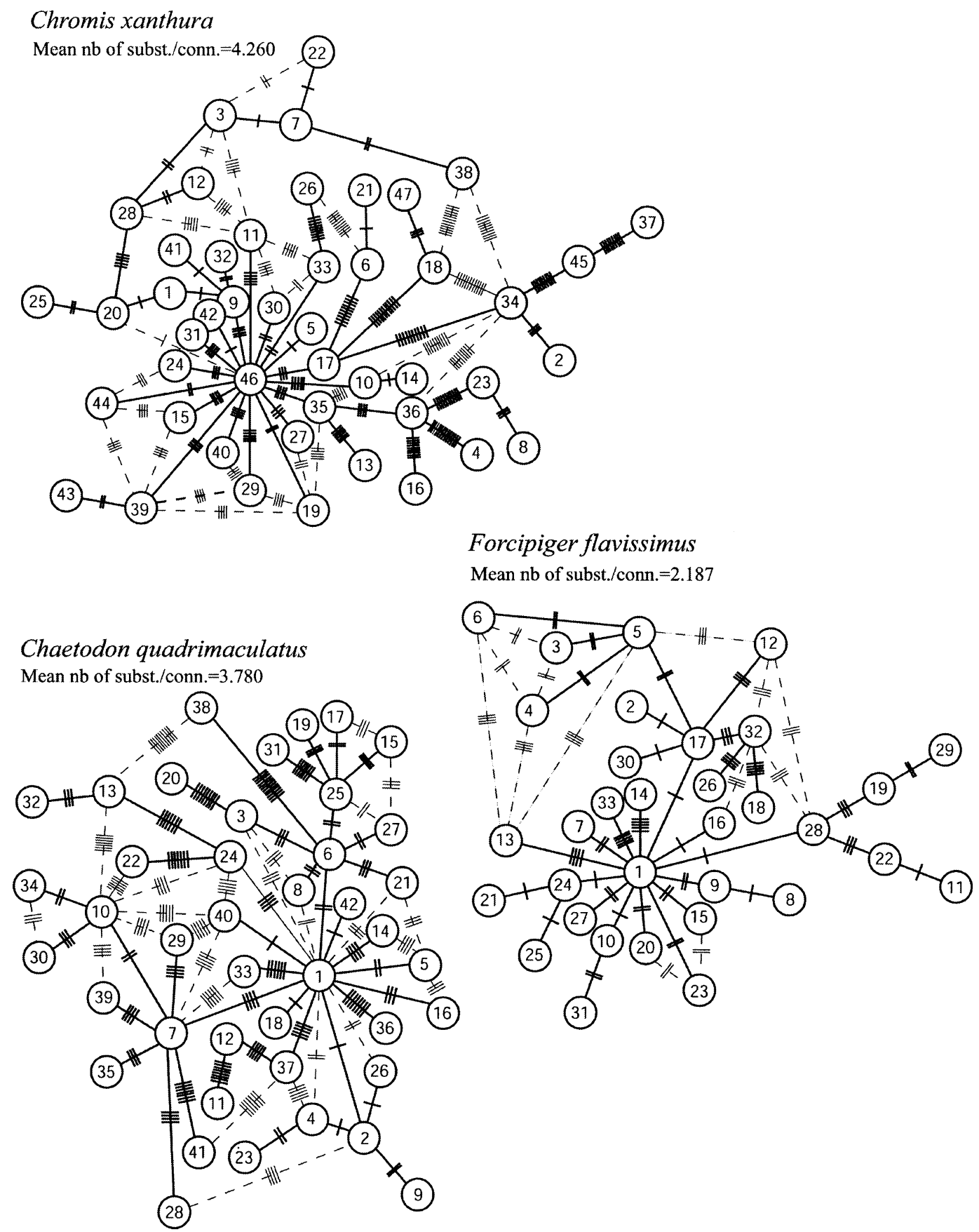

FIG. 2. Continued.

for all the species in this study did not reject Rogers' (1995) model of sudden expansion $(P>0.368)$. However, three species showed a bimodal distribution: Chromis xanthura, Chaetodon citrinellus, and Dascyllus aruanus.

Pairwise mismatch distributions obtained for each species revealed three kinds of distributions. The first was represented by Pomacentrus pavo and Chrysiptera glauca, which both had a high proportion $(42.77 \%$ and $24.66 \%$, respectively) of paired comparisons between identical alleles (zero sites different). The range of these two distributions was small (Pomacentrus pavo, range: 0-1.64\%, mode: 0\%; and Chrysiptera glauca, range 0-2.02\%, mode: 0.5\%). Opposite this kind of distribution, pairwise mismatch distributions of the three species inhabiting the outer slope (Chaetodon quadrimaculatus, Chromis xanthura, and Forcipiger flavissimus) covered a large range of number of pairwise differences (e.g., 0-7.92\% of sequence divergence for Chromis xanthura), with fewer pairs between identical alleles $(<0.4 \%$ for the three 
TABLE 3. Overall mean distance and maximum divergence between individual sequences within each species. Distances are calculated according to the HKY 85 distance model of nucleotide substitutions (and its standard deviation, SD; Hasegawa et al. 1985), with a gamma correction for species where indicated by the shape parameter $\alpha$ (issued from neighbor-joining analyses computed in PAUP 4.0; Swofford 1998).

\begin{tabular}{lccr}
\hline \hline & & $\begin{array}{c}\text { Overall mean } \\
\text { distance (\%) }\end{array}$ & $\begin{array}{c}\text { Max } \\
\text { divergence } \\
(\%)\end{array}$ \\
\hline Outer slope species & & & \\
$\quad$ Chaetodon quadrimaculatus & 0.25 & $2.45(1.31)$ & 8.31 \\
$\quad$ Chromis xanthura & 0.22 & $4.57(2.38)$ & 12.58 \\
Forcipiger flavissimus & 0.97 & $2.72(1.13)$ & 7.30 \\
Lagoon species & & & \\
$\quad$ Chaetodon citrinellus & 0.05 & $1.44(1.16)$ & 4.97 \\
Chrysiptera glauca & $\infty$ & $0.39(0.37)$ & 2.06 \\
Dascyllus aruanus & 0.22 & $2.39(1.58)$ & 8.05 \\
Pomacentrus pavo & $\infty$ & $0.26(0.30)$ & 1.66 \\
\hline
\end{tabular}

outer-slope species). Outer-slope species also revealed distributions shifted toward high numbers of pairwise differences: the first mode of Chromis xanthura distribution and modes of Chaetodon quadrimaculatus and Forcipiger flavissimus distributions ranged between 1.77 and $2.31 \%$ of sequence divergence. Finally, between these two extreme distributions, Chaetodon citrinellus and Dascyllus aruanus showed intermediate distributions with two modes. The first mode corresponded to within-clade comparisons (with 0.5 and $0.6 \%$ of sequence divergence, respectively), and the second to between-clade comparisons (with more than $2.00 \%$ of sequence divergence for the two species). The proportion of paired comparisons between identical alleles for these two species was $5.13 \%$ and $1.41 \%$ of the total comparisons, respectively.

Over all the species, lagoonal species showed significantly higher proportions of pairs between identical alleles than outer-slope species (WMW test, $P=0.034$ ). Moreover, the difference of proportions between pelagic and benthic eggs species was not significant (WMW test, $P=0.479$ ).

The Galtier et al. (2000) test for Pomacentrus pavo and Chrysiptera glauca revealed a strong and highly significant recent bottleneck occurring between 0.068 and $0.096 \times 2 N_{e}$ generations ago. Likelihood-ratio tests computed from loglikelihood obtained under "no founder event'" and "bottle- neck' models equal 16.98 for Pomacentrus pavo and 15.77 for Chrysiptera glauca (critical $\chi^{2}$ value $=5.99$ and $9.21, P$ $<0.05$ and 0.01 , respectively, with $\mathrm{df}=2$ ).

\section{DisCUSSION}

\section{Impact of Reproductive Strategy}

None of the diversity indices and sequence divergence obtained from D-loop sequences of the seven species showed significant differences in mtDNA diversity between Chaetodontidae (pelagic eggs) and Pomacentridae (benthic eggs). Moreover, there was no more geographic structure for Pomacentridae than for Chaetodontidae, despite a pelagic larval duration twice as long for species laying pelagic eggs than for benthic egg species (Hourigan and Reese 1987; Wellington and Victor 1989). Furthermore, the species with the longest larval duration involved in our study, Forcipiger flavissimus (up to 57 days; Brothers and Thresher 1985) is the only species that showed a significant genetic differentiation between the farthest islands. Even if interconnection of populations can be considered a result of larval dispersion, the range of geographic distances between isolated islands used in our study (up to $1500 \mathrm{~km}$ ) did not reveal geographically restricted haplotypes (endemism). This result suggests widespread dispersal for all species based on the population genetic information carried by D-loop sequence.

Such a pattern is comparable to the results of a survey from the Caribbean in which no population differentiation was found over large spatial scales in most species surveyed using restriction endonuclease analyses on mtDNA (Shulman and Bermingham 1995). Similar to this previous survey, neither the egg type (linked to the length of the larval life), nor oceanic currents within the area could predict a geographic structure in coral reef fish populations within French Polynesia. A similar result was obtained for Dascyllus trimaculatus (Bernardi et al. 2001), which has a pelagic larval stage with mean duration of 26 days: little genetic variation was obtained between Moorea and Rangiroa samples $\left(F_{\mathrm{ST}}=0.01\right)$ and the authors concluded that this species was an effective disperser within relative small spatial scales. Finally, these results also fit with the results of our previous study (Fauvelot and Planes 2002), in which little genetic differentiation was found between populations of the eight species and no relationship between genetic and

TABLE 4. Hierarchical analysis of molecular variance of mtDNA control region haplotypes. The percentage of variation given is the percentage of molecular variance attributed to variance obtained within populations. $\Phi$-statistics within populations $\left(\Phi_{\mathrm{ST}}\right)$ correspond to the fixation index identical to the weighted average $F$-statistic defined by Weir and Cockerham (1984). Significance $(P)$ is defined as the probability of finding a higher variance component and $\Phi$-statistic than the observed value and was tested using a nonparametric permutation approach described in Excoffier et al. (1992), with 1000 permutations or more of the dataset.

\begin{tabular}{|c|c|c|c|c|}
\hline Species & $\begin{array}{l}\text { Variance } \\
\text { component }\end{array}$ & $\begin{array}{l}\text { Percentage } \\
\text { of variation }\end{array}$ & $\begin{array}{l}\text { Fixation } \\
\text { index }\end{array}$ & $P$ \\
\hline Chromis xanthura & 5.61340 & 98.99 & $\Phi_{\mathrm{ST}}=0.0010$ & 0.352 \\
\hline Chaetodon citrinellus & 2.83906 & 98.44 & $\Phi_{\mathrm{ST}}=0.0156$ & 0.265 \\
\hline Chrysiptera glauca & 0.77029 & 99.91 & $\Phi_{\mathrm{ST}}=0.0009$ & 0.285 \\
\hline Dascyllus aruanus & 3.42578 & 98.05 & $\Phi_{\mathrm{ST}}=0.0195$ & 0.292 \\
\hline Pomacentrus pavo & 0.47717 & 100.92 & $\Phi_{\mathrm{ST}}=-0.0092$ & 0.629 \\
\hline
\end{tabular}






FIG. 3. Results of Tajima's $D$-test ( $D$ value and its associated probability; Tajima 1989), pairwise mismatch distributions (Rogers and Harpending 1992) and Rogers' (1995) model of sudden population expansion (simulated) for each species.

geographic distances and/or between genetic patterning and the reproductive strategy was observed. The lack of these relationships was interpreted as resulting from an island model applicable to all the species, in which random larval exchanges in space and time would promote such genetic patterns (Fauvelot and Planes 2002).

These three studies (Shulman and Bermingham 1995; Bernardi et al. 2001; Fauvelot and Planes 2002) together with the present study show that larval duration does not affect geographic structure. However, the lack of genetic structuring relative to larval duration found in these four studies is opposite to what Doherty et al. (1995) found within the Great Barrier Reef. The analysis of enzymatic polymorphism of seven coral reef fish species, providing a range of pelagic larval durations, revealed a significant correlation between genetic variation between and the mean larval duration of the species. Nevertheless, their empirical relationship seems only to apply within the context of the highly connected Great 
Barrier Reef (Doherty et al. 1995). The potential connectivity of reefs could explain this relationship by itself. Even if larvae of coral reef fish present variable pelagic duration, the competence periods (i.e., period when they become morphologically ready to settle), measured by the plasticity of the larval duration, are about equal. Therefore, in an island system, regardless of the time spent in the ocean, larvae with various pelagic durations seem to have the same low probability to find a suitable isolated environment to settle when they are competent. The relationships between genetic and geographic distances and/or between level of genetic divergence and pelagic larval duration would then not be expected in an island environment.

However, genetic analyses of gene flow between populations alone may not be able to resolve alternative scenarios responsible for current genetic patterning because of the possible youth of divergence (Grant and Bowen 1998). In fact, genetic patterns observed using allozymes polymorphism in our previous study (Fauvelot and Planes 2002) could also be interpreted as a result of nonstable population size. Nevertheless, the impossibility of assessing coalescence time with allozyme polymorphism of populations does not reject the hypothesis of the competence duration influence on genetic structure, even if we take into account the demographic history population impact on genetic patterning.

\section{Impact of Habitat Preference}

Significant differences in mtDNA diversity between lagoonal species and species inhabiting the outer slope have been demonstrated for haplotype diversity, sequence divergence and the proportion of paired comparisons between identical alleles. This difference is also highlighted when describing minimum spanning networks, with species inhabiting lagoons showing smaller numbers of haplotypes, smaller numbers of nucleotide substitutions between haplotypes, and greater numbers of individuals sharing the same haplotypes than species inhabiting the outer slope. What can explain lower mtDNA diversity for lagoonal species than for outer-slope species? Several scenarios can reach the pattern we observed: small local effective population size of lagoon species, nonequal mutation rates among species, differences in selection pressure among species, and recent population size reductions of lagoonal species.

The small local effective population size hypothesis suggests that genetic drift would maintain a small number of haplotypes if local populations are small, since the genetic diversity $(H)$ is a direct function of the effective population size $\left(N_{e}\right)$ and the mutation rate $(\mu)$, according to the model $H=4 N_{e} \mu /\left(4 N_{e} \mu+1\right)$ (Kimura 1983; Nei and Graur 1984). Small local effective population sizes are expected in isolated populations in which gene flow is not enough powerful to encounter genetic drift. This hypothesis does not fit our data since lagoonal species did not express more geographical structure than did outer-slope species. High variance in reproductive success can also lead to small local effective population size, with geographic homogeneity if gene flow is high enough to promote the propagation of weak numbers of haplotypes (Avise 1994; Schields and Gust 1995). This hypothesis has already been suggested to explain low levels of
mtDNA divergence and diversity in coral reef fishes coupled with no geographical patterning (Shulman and Bermingham 1995), considering the extremely low and presumably highly stochastic survival rate of pelagic larvae. But regarding our species design, mixing the species inhabiting different habitats within two families having different reproductive strategy, it would be a coincidence if lagoonal species of Chaetodontidae and Pomacentridae were the only ones that suffer reproductive success variance. Therefore, if gene flow is high enough to homogenize genetic structure, the effective size of local populations is then close to the effective population size over all populations (Slatkin 1977). In this case, coalescence times in a local population are about the same as in all locals populations connected by gene flow. Finally, if the amount of exchange is correct, general coalescence over all the populations of each species can be analyzed instead of local populations coalescences.

The nonequal mutation rate among species hypothesis suggests that variations in D-loop sequences evolution rate $(\mu)$ could promote variations in haplotype diversity according to the model $H=4 N_{e} \mu /\left(4 N_{e} \mu+1\right)$ (Kimura 1983; Nei and Graur 1984). A smaller evolutionary mutation rate for lagoonal species than for outer-slope species would then explain smaller mtDNA diversity for lagoonal species compared to outer-slope species. However, there is no evidence in the literature on sister species (or closely related ones) differing in mutation rate. Dascyllus aruanus and D. trimaculatus are two closely related species (Bernardi and Crane 1999). They both showed the same pattern of genetic structure (genetic homogeneity within French Polynesia; Bernardi et al. 2001) although they inhabit different parts of the reef (D. trimaculatus inhabits the outer slope in French Polynesia) but they showed different haplotype phylogenies: D. trimaculatus populations showed higher haplotype diversity and divergence than $D$. aruanus populations. The same remark can be made about Chaetodontids from this study since Chaetodon citrinellus and Chaetodon quadrimaculatus, despite shared life-history traits and geographical structure, showed differences in mtDNA variability. Finally, we cannot reject the hypothesis of lower mutation rate explaining low genetic diversity because we cannot conduct molecular clock tests (D-loop sequences are too divergent among species to be aligned), but it would be a coincidence to observe, within two genera, lower mutation rates for lagoonal species than for outer-slope species.

The selection hypothesis suggests that smaller numbers of haplotypes for lagoonal species are expected if selection pressures differently affect populations relative to their habitat preference. Tajima's $D$-tests conducted on overall sequences of each species revealed negative and significant $D$-values for five of the seven species, which provides evidence of deviations from neutrality that can be the result of both selection and population expansion (Tajima 1989). Poissonlike distributions of the number of nucleotide differences were obtained for each species. This distribution is generally attributed to mutation-drift disequilibrium caused by explosive population growth (Rogers and Harpending 1992). Because we cannot reject Rogers' (1995) model of sudden expansion, our data suggest that the seven species of our study have undergone population expansion and that selection is 
unlikely to have created differences in mtDNA variability relatively to species habitat preferences.

Finally, the reduction of effective population size hypothesis can explain such differences in mtDNA diversity between lagoonal species and outer-slope species. Several historical demographic events can lead to population size reductions, like overharvesting (Camper et al. 1993), recent habitat reductions (Shulman and Bermingham 1995), population bottlenecks (Gold et al. 1994), founder events or other "demographic events", (Dodson et al. 1991). Considering the eustatic history of the central Pacific during the late Holocene, when minimum sea-level was $120 \mathrm{~m}$ below the present level, approximately 18,000 years ago (Bard et al. 1996), the low mtDNA diversity indices and pairwise mismatch distributions observed in all lagoonal species are more consistent with the hypothesis of population size reduction events consequent to Holocene sea-level regression than with any of the hypotheses previously developed. The lack of greater geographic divergence between populations of lagoonal species compared to outer-slope species also highlights the population size reduction hypothesis, extended to all lagoonal populations (local population size reductions of lagoonal species would have created a higher level of divergence for lagoonal species than for outer-slope species). In fact, the Holocene sea-level regression that has led to the drying out of all atoll lagoons that were 40-70 m deep (Bard et al. 1996) and the probable subsequent reduction of population size might have caused local extinction of some species restricted to this habitat. Finally, the current lagoonal structure of atolls reappeared when the present sea level was reached, between 5000 and 6000 years ago in French Polynesia (Pirazzoli and Montaggioni 1988). In contrast to lagoonal species, species inhabiting the outer slope did not suffer such a sea-level crisis since their habitat, the outer reef, persisted during low sea level, leading to reduction of reef area, probably like that observed in the Caribbean (Shulman and Bermingham 1995). This scenario is highlighted by the Galtier et al. (2000) test that demonstrated a severe and recent bottleneck for Pomacentrus pavo and Chrysiptera glauca, explaining their reduced mtDNA diversity. However, we could not reach such a conclusion for the two other species residing in lagoonal habitats, Dascyllus aruanus and Chaetodon citrinellus, because the Galtier et al. test could not be computed for both species. Both $C$. citrinellus and $D$. aruanus show multiple and/or repeated substitutions at the same nucleotide site, which may originate from homoplasic sites (cf. hot spots) in the sequence (Jazin et al. 1998). Therefore, the coalescence-based maximum-likelihood method could not be used to test for the origin of low genetic diversity in the sequences.

Pairwise mismatch distributions of alleles are also in agreement with the hypothesis of stronger population size reduction for lagoonal species compared to outer-slope species since the distributions drawn for each species clearly show different patterns. Lagoonal species distributions are shifted toward weak numbers of differences compared to outer-slope species (even if $C$. citrinellus and D. aruanus showed multimodal distributions). Even if all populations of all the seven species have undergone rapid population growth, suggested by the Poisson-like distributions, differences in distribution modes and ranges suggest variable strength and/or time of expansion of French Polynesian populations according to the species' habitat preferences. Pairwise mismatch distribution of outer-slope species are more consistent with a weak and/ or old bottleneck, followed by a population expansion, because of the lack of "satellite", haplotypes distinguished by one or two mutations, whereas lagoonal species might have undergone a more recent and/or strong bottleneck, probably with a different degree of strength considering the multimodal distributions of $C$. citrinellus and D. aruanus. This hypothesis would explain the high proportion of paired comparisons between identical alleles observed in lagoonal species, particularly high for Pomacentrus pavo and Chrysiptera glauca. Differences in distribution of pairwise comparisons for lagoonal species (one or two modes) would suggest different demographic events (bottleneck or founder event). Single modal distributions of $P$. pavo and $C$. glauca would suggest recent colonization of this species in French Polynesian lagoons (founder event) and then would classify these two species in the first category of species described by Grant and Bowen (1998), with both low haplotype and nucleotide diversities. Bimodal distributions of Chaetodon citrinellus and Dascyllus aruanus would be more consistent with regionwide bottlenecks, with persistence of ancestral polymorphism, and then would classify these two species in the second category of species described by Grant and Bowen (1998), with high haplotype and low nucleotide diversities. It should be noted that similar patterns with bipartite structure in allele phylogeny have already been observed within the same area for gastropods with marine larval stages, and the authors concluded an independent colonization of French Polynesia from distant islands (Myers et al. 2000).

Finally, genetic diversity in allozyme loci from our previous study (Fauvelot and Planes 2002) confirmed population size reduction followed by rapid population growth for lagoonal species since we had found higher multilocus heterozygosity levels for lagoonal species than for outer-slope species on enzymatic loci. Indeed, during population declines, the loss of genetic diversity would be accelerated in mtDNA relative to nuclear DNA due to the lower effective population size of this maternally inherited genome (Grant and Bowen 1998). Hence, allozyme diversity might be higher than mtDNA diversity shortly after population crashes.

In conclusion, the present results, together with previous data, confirm that lagoonal fish species uniformly express low genetic diversity indices compared to outer-slope related species, which is due to effective population size reduction relative to lagoon habitat instability during sea-level variations. Similarly, the analysis of the pearl oyster (Pinctada margaritifera), a mollusk that occupies lagoonal habitats in French Polynesia, showed a low level of haplotype diversity and significant negative Tajima's D-values (Arnaud 2000). Pinctada margaritifera still shows low genetic diversity indices, certainly because it mostly inhabits lagoons (Zanini and Salvat 2000). As seen in to the fish analysis in the present work, the instability of lagoonal habitats has probably contributed to reducing the genetic variability of the species.

Finally, in our study, mtDNA variations of diversity among species are the legacy of historical events and no conclusions can be made about dispersal capabilities for coral reef species involved in our study. Indeed, our results clearly demon- 
strated that the mutation-genetic drift equilibrium has not yet been reached for any of the seven species and that genetic patterning cannot be interpreted as a result of present gene flow. Our study underlines the necessity of considering the demographic history of a species when looking at its genetic structure in terms of the interpretation of present population interconnections.

\section{ACKNOWLEDGMENTS}

We thank anonymous reviewers for their valuable suggestions and comments. Special thanks go to F. Bonhomme, N. Galtier, J-D. Durand and B. Quenouille who greatly contributed to this work through discussion. We gratefully acknowledge the assistance in sampling specimens: R. Galzin and Y. Chancerelle for collecting specimens from Tetiaroa and additional ones from Takapoto; R. Wan for the facilities he offered in Marutea; G. Remoissonet and H. Leduc providing Service de la Pêche facilities in Rangiroa and Takapoto. This study was supported in part by the David and Lucille Packard Foundation Partnership for Interdisciplinary Studies of Coastal Oceans program, by grants from the French National Program on Biodiversity and by the Total-Elf-Fina foundation.

\section{Literature Cited}

Allen, G. R. 1991. Damselfishes of the world. Mergus Press, Hong Kong.

Allen, G. R., R. Steene, and M. Allen. 1998. A guide to angelfishes and butterflyfishes. Odyssey Publishing/Tropical Reef Research, Perth, Australia.

Arnaud, S. 2000. Flux génique et phylogéographie comparée de deux espèces de bivalves du Pacifique: Pinctada mazatlanica et P. margaritifera, marqueurs mitochondriaux et nucléaires. Ph.D. diss. University of Montpellier II, France.

Avise, J. C. 1994. Molecular markers, natural history, and evolution. Chapman and Hall, New York.

. 1998. The history and purview of phylogeography: a personal reflection. Mol. Ecol. 7:371-379.

2000. Phylogeography: the history and formation of species. Harvard Univ. Press, Cambridge, MA.

Bard, E., B. Harmelin, M. Arnold, L. Montaggioni, G. Cabioch, G. Faure, and F. Rougerie. 1996. Deglacial sea level record from Tahiti corals and the timing of global melt water discharge. Nature 382:241-244.

Bell, L. J., J. T. Moyer, and K. Nomachi. 1982. Morphological and genetic variation in Japanese populations of the anemone fish Amphiprion clarkii. Mar. Biol. 72:99-108.

Benzie, J. A., and S. T. Williams. 1997. Genetic structure of giant clam (Tridacna maxima) populations in the west Pacific is not consistent with dispersal by present-day ocean currents. Evolution 51:768-783.

Bernardi, G., and N. L. Crane. 1999. Molecular phylogeny of the humbug damselfishes inferred from mtDNA sequences. J. Fish. Biol. 54:1210-1217.

Bernardi, G., S. J. Holbrook, and R. J. Schmitt. 2001. Gene flow at three spatial scales in a coral reef fish, the three-spot dascyllus, Dascyllus trimaculatus. Mar. Biol. 138:457-465.

Brothers, E. B., and R. E. Thresher. 1985. Pelagic duration, dispersal and the distribution of Indo-Pacific coral reef fishes. Pp. 53-69 in M. L. Reaka, ed. The ecology of deep and shallow coral reefs. NOAA symposium series on undersea research no. 3. U.S. Department of Commerce, Washington, DC.

Bucklin, A., and P. H. Wiebe. 1998. Low mitochondrial diversity and small effective population sizes of the copepods Calanus finmarchicus and Nannocalanus minor: possible impact of climatic variation during recent glaciation. J. Hered. 89:383-392.
Camper, J. D., R. C. Barber, L. R. Richardson, and J. R. Gold 1993. Mitochondrial DNA variation among red snapper $(\mathrm{Lu}-$ tjanus campechanus) from the Gulf of Mexico. Mol. Mar. Biol. Biotech. 2:154-161.

Dodson, J. J., J. E. Carscadden, L. Bernatchez, and F. Colombani. 1991. Relationship between spawning mode and phylogenetic structure in mitochondrial DNA of North Atlantic capelin Mallotus villosus. Mar. Ecol. Prog. Ser. 76:103-113.

Doherty, P. J., S. Planes, and P. Mather. 1995. Gene flow and larval duration in seven species of fish from the Great Barrier Reef. Ecology 76:2373-2391.

Excoffier, L., and P. E. Smouse. 1994. Using allele frequencies and geographic subdivision to reconstruct gene genealogies within a species. Molecular variance parsimony. Genetics 136:343-359.

Excoffier, L., P. E. Smouse, and J. M. Quattro. 1992. Analysis of molecular variance inferred from metric distances among DNA haplotypes: application to human mitochondrial DNA restriction data. Genetics 131:479-491.

Fauvelot, C., and S. Planes. 2002. Understanding origins of presentday genetic structure in marine fish: biologically or historically driven patterns? Mar. Biol. 141:773-788.

Galtier, N., F. Depaulis, and N. H. Barton. 2000. Detecting bottlenecks and selective sweeps from DNA sequence polymorphism. Genetics 155:981-987.

Galzin, R. 1987. Structure of fish communities of French Polynesia coral reefs. 1. Spatial scales. Mar. Ecol. Prog. Ser. 41:129-136.

Gold, J. R., and L. R. Richardson. 1998. Mitochondrial DNA diversification and population structure in fishes from the Gulf of Mexico and Western Atlantic. J. Hered. 89:404-414.

Gold, J. R., L. R. Richardson, C. Furman, and F. Sun. 1994. Mitochondrial DNA diversity and population structure in marine fish species from the Gulf of Mexico. Can. J. Fish. Aquat. Sci. 51:205-214.

Grant, W. S., and B. W. Bowen. 1998. Shallow population histories in deep evolutionary lineages of marine fishes: insights from sardines and anchovies and lessons for conservation. J. Hered. 89:415-426.

Hasegawa, M., K. Kishino, and T. Yano. 1985. Dating the humanape splitting by a molecular clock of mitochondrial DNA. J. Mol. Evol. 22:160-174.

Hewitt, G. 2000. The genetic legacy of the Quaternary ice ages. Nature 405:907-913.

Hickerson, M. J., and J. R. P. Ross. 2001. Post-glacial population history and genetic structure of the northern clingfish (Gobbiesox maeandricus), revealed from mtDNA analysis. Mar. Biol. 138: 407-419.

Hourigan, T. F., and E. S. Reese. 1987. Mid-ocean isolation and the evolution of Hawaiian reef fishes. Trends Ecol. Evol. 2: 187-191.

Hudson, R. R. 1990. Gene genealogies and the coalescent process. Pp. 1-44 in D. Futuyma and J. D. Antonovics, eds. Oxford surveys in evolutionary biology. Oxford Univ. Press, New York.

Jazin, E., H. Soodyall, P. Jalonen, E. Lindholm, M. Stoneking, and U. Gyllensten. 1998. Mitochondrial mutation rate revisited: hot spots and polymorphism. Nature Genet. 18:109-110.

Kimura, M. 1980. A simple method for estimating evolutionary rates of base substitutions through comparative studies of nucleotide sequences. J. Mol. Evol. 16:111-120.

1983. The neutral theory of molecular evolution. Cambridge Univ. Press, Cambridge, U.K.

Koehn, R. K., R. I. E. Newell, and F. Immermann. 1980. Maintenance of an aminopeptidase allele frequency cline by natural selection. Proc. Natl. Acad. Sci. USA 77:5385-5389.

Lacson, J. M. 1992. Minimal genetic variation among samples of 6 species of coral reef fishes collected at La Parguera, Puerto Rico and Discovery Bay, Jamaica. Mar. Biol. 112:327-331.

Lacson, J. M., V. M. Riccardi, S. W. Calhoun, and D. C Morizot. 1989. Genetic differentiation of bicolour damselfish (Eupomacentrus partitus) populations in Florida Keys. Mar. Biol. 103: $445-451$.

Lavery, S., C. Moritz, and D. R. Fielder. 1996. Indo-Pacific population structure and evolutionary history of the coconut crab, Birgus latro. Mol. Ecol. 5:557-570. 
Lee, W., J. Conroy, W. H. Howell, and T. D. Kocher. 1995. Structure and evolution of teleost mitochondrial control region. J. Mol. Evol. 41:54-66.

Lemaire, C., G. Allegrucci, M. Naciri, L. Bahri-Sfar, H. Kara, and F. Bonhomme. 2000. Do discrepancies between microsatellite and allozyme variation reveal differential selection between sea and lagoon in sea bass (Dicentrarchus labrax). Mol. Ecol. 9: $457-467$.

McGlashan, D. J., and J. M., Hughes. 2001. Low level of genetic differentiation among populations of the freshwater fish Hypseleotris compressa (Gobiidae: Eleotridinae): implications for its biology, population connectivity and history. Heredity 86: 222-223.

Meyer, A. 1994. Molecular phylogenetic studies of fish. Pp. 219 249 in A. R. Beaumont, ed. Genetics and evolution of aquatic organisms. Chapman and Hall, London.

Myers, M. J., C. P. Meyer, and V. H. Resh. 2000. Neritid and thiarid gastropods from French Polynesian streams: how reproduction (sexual, parthenogenetic) and dispersal (active, passive) affect population structure. Freshw. Biol. 44:535-545.

Nei, M. 1987. Molecular evolutionary genetics. Columbia Univ. Press, New York.

Nei, M., and D. Graur. 1984. Extent of protein polymorphism and the neutral mutation theory. Evol. Biol. 17:73-118.

Nelson, J. S., R. J. Hoddell, L. M. Chou, W. K. Chan, and V. P. E. Phang. 2000. Phylogeographic structure of false clownfish, Amphiprion ocellaris, explained by sea level changes on the Sunda shelf. Mar. Biol. 37:727-736.

Palumbi, S. R. 1994. Genetic divergence, reproductive isolation, and marine speciation. Annu. Rev. Ecol. Syst. 25:547-572.

Palumbi, S. R., G. Grabowsky, T. Duda, N. Tachino, and L. Geyer. 1997. Speciation and the evolution of population structure in tropical Pacific sea urchins. Evolution 51:1506-1517.

Pirazzoli, P. A., and L. Montaggioni. 1988. Holocene sea level changes in French Polynesia. Palaeogeogr. Palaeoclimatol. Palaeoecol. 68:153-175.

Planes, S. 1993. Genetic differentiation in relation to restricted larval dispersal of the convict surgeon fish, Acanthurus triostegus, in French Polynesia. Mar. Ecol. Prog. Ser. 98:237-246.

Planes, S., F. Bonhomme, and R. Galzin. 1993. Genetic structure of Dascyllus aruanus populations in French Polynesia. Mar. Biol. 117:665-674.

—_ 1996. A genetic metapopulation model for reef fishes in oceanic islands: the case of the surgeonfish, Acanthurus triostegus. J. Evol. Biol. 9:103-117.

Planes, S., M. Parroni, and C. Chauvet. 1997. Evidence of limited gene flow in three coral reef fish species in the lagoon of New Caledonia. Mar. Biol. 130:361-368.

Pogson, G. H., K. A. Mesa, and R. G. Boutilier. 1995. Genetic population structure and gene flow in the Atlantic cod Gadus morhua: a comparison of allozyme and nuclear RFLP loci. Genetics 139:375-385.

Posada, D., and K. A. Crandall. 1998. Modeltest: testing the model of DNA substitution. Bioinformatics 14:817-818.

_- 2001. Intraspecific gene genealogies: trees grafting into networks. Trends Ecol. Evol. 16:37-45.
Powers, D. A., and P. M. Schulte. 1998. Evolutionary adaptations of gene structure and expression in natural populations in relation to a changing environment: a multidisciplinary approach to address the million-year saga of a small fish. J. Exp. Zool. 282:71-94.

Riginos, C., and B. C. Victor. 2001. Larval spatial distributions and other early life-history characteristics predict genetic differentiation in eastern Pacific blennioid fishes. Proc. R. Soc. Lond. 268:1931-1936.

Rogers, A. R. 1995. Genetic evidence for a Pleistocene population explosion. Evolution 49:608-615.

Rogers, A. R., and H. Harpending. 1992. Population growth makes waves in the distribution of pairwise genetic distances. Mol. Biol. Evol. 9:552-569.

Sambrook, J., E. F. Fritsch, and T. Maniatis. 1989. Molecular cloning: a laboratory manual, 2d. ed. Cold Spring Harbor Laboratory, Cold Spring Harbor, New York.

Schields, G. F., and J. R. Gust. 1995. Lack of geographic structure in mitochondrial DNA sequences of Bering Sea walleye pollock, Theragra chalcogramma. Mol. Mar. Biol. Biotech. 4:69-82.

Schneider, S., D. Roessli, and L. Excoffier. 2000. Arlequin Ver. 2.000: a software for population genetics data analysis. Genetics and Biometry Laboratory, University of Geneva, Switzerland.

Shulman, M. J., and E. Bermingham. 1995. Early life histories, ocean currents, and the population genetics of Caribbean reef fishes. Evolution 49:897-910.

Slatkin, M. 1977. Gene flow and genetic drift in species subject to frequent local extinctions. Theor. Popul. Biol. 12:253-262.

Swofford, D. L. 1998. PAUP*. Phylogenetic analysis using parsimony (*and other methods). Sinauer Associates, Sunderland, MA.

Tajima, F. 1989. Statistical methods for testing the neutral hypothesis by DNA polymorphism. Genetics 123:585-595.

Tamura, K., and M. Nei. 1993. Estimation of the number of nucleotide substitutions in the control region of mitochondrial DNA in humans and chimpanzees. Mol. Biol. Evol. 10:512-526.

Thresher, R. E. 1991. Geographic variability in the ecology of coral reef fishes: evidence, evolution and possible implications. Pp. 401-436 in P. F. Sale, ed. The ecology of fishes on coral reefs. Academic Press, San Diego, CA.

Waples, R. S. 1987. A multispecies approach to the analysis of gene flow in marine shore fishes. Evolution 41:385-400.

Weir, B. S., and C. C. Cockerham. 1984. Estimating F-statistics for the analysis of population structure. Evolution 38:1358-1370.

Wellington, G. M., and B. C. Victor. 1989. Planktonic larval duration of one hundred species of Pacific and Atlantic damselfishes (Pomacentridae). Mar. Biol. 101:557-567.

Winans, G.A. 1980. Geographic variation in the milkfish Chanos chanos. I. Biochemical evidence. Evolution 34:558-574.

Yang, Z. 1996. Among-site rate variation and its impact on phylogenetic analysis. Trends Ecol. Evol. 11:367-372.

Zanini, J.-M., and B. Salvat. 2000. Assessment of deep water stocks of pearl oysters at Takapoto Atoll (Tuamotu Archipelago, French Polynesia). Coral Reefs 19:83-87.

Corresponding Editor: G. Wallis 